\title{
Accumulation of Tripeptide Derivatives by Mutants of Cephalosporium acremonium
}

\author{
Hideo ShIRAfujI, Yukio FujisaWa, Makoto KIDA, Toshihiko KanZaKI \\ and Masahiko YonedA
}

Central Research Division, Takeda Chemical Industries, Ltd., Yodogawa-ku, Osaka 532, Japan

Received September 6, 1978

\begin{abstract}
The two $\beta$-lactam antibiotics produced by Cephalosporium acremonium ATCC 14553, cephalosporin $\mathrm{C}$ and penicillin $\mathrm{N}$, have been proposed to be biosynthesized through the peptide, $\delta$-(L- $\alpha$-aminoadipyl)-L-cysteinyl-D-valine.

Many $\beta$-lactam negative mutants were derived from the strain No. 52, which was a more potent producer of the $\beta$-lactam antibiotics than the parent strain, $C$. acremonium ATCC 14553. Some of them were found to accumulate two sulfur-containing peptides. These compounds were isolated from the culture filtrate of one of the mutants, $\mathrm{N}-2$ and determined to be the dimer of $\delta$-(L- $\alpha$-aminoadipyl)-L-cysteinyl-D-valine and the S-methylthio derivative of the tripeptide.
\end{abstract}

The biosynthesis of $\beta$-lactam antibiotics has been extensively studied by biochemical methods and tracer experiments. Some workers ${ }^{1 \sim 3 \gamma}$ proposed the "tripeptide theory" in which $\beta$ lactam antibiotics are synthesized through the formation and cyclization of the tripeptide, $\delta$ (L- $\alpha$-aminoadipyl)-L-cysteinyl-D-valine.

To elucidate the biosynthetic pathway of $\beta$ lactam antibiotics, it was examined that mutants blocked in the pathway accumulated its intermediates or their derivatives. A number of $\beta$-lactam negative mutants were derived from $C$. acremonium ATCC 14553 which produces two $\beta$-lactam antibiotics, cephalosporin $\mathrm{C}$ (CPC) and penicillin $\mathrm{N}$ (PCN). ${ }^{4}$ One of the mutants, $\mathrm{N}-2$ was found to accumulate two compounds which contained sulfur and were positive to ninhydrin reaction. This paper deals with the isolation and the determination of the structure of the two compounds.

\section{MATERIALS AND METHODS}

Microorganisms. The strains used in this study were a potent CPC-producing strain, No. 52 derived from C.acremonium ATCC 14553 and $\beta$-lactam negative mutants from the strain, No. 52. One of the PCN negative mutants, $\mathrm{N}-2$ was used for the preparation of the sulfur-containing compounds.

Culture media and conditions. The composition of the media and the culture conditions were the same as reported previously, ${ }^{5)}$ except the fermentation period ( 5 days).

Selection of $\beta$-lactam negative mutants. The $\beta$ lactam negative mutants were selected independently as PCN or CPC negative mutants from the survivors of the conidia $\left(10^{7} \sim 10^{8} / \mathrm{ml}\right)$ of the strain, No. 52 after exposure to $\mathrm{N}$-methyl- $\mathrm{N}^{\prime}$-nitro- $\mathrm{N}$-nitrosoguanidine $(100 \sim 500 \mu \mathrm{g} / \mathrm{ml})$ or UV irradiation $(10 \sim 30 \mathrm{~min}, 30 \mathrm{~cm}$ under a $10 \mathrm{~W}$ lamp). Four to six survivors were picked up onto a nutrient agar plate $(9 \mathrm{~cm}$ diameter of petri dish) and it was incubated at $28^{\circ} \mathrm{C}$. After 6 day incubation, the productivity of CPC was tested by overlaying $4 \mathrm{ml}$ of soft nutrient agar containing Alcaligenes faecalis ATCC 8750 and $1 \times 10^{5}$ units of penicillinase to destroy $\mathrm{PCN}$.

As for PCN productivity, colonies grown for 4 days were tested by using the mutant No. 55 of Sarcina lutea $\mathrm{PCI} 1001 .^{5)}$ Colonies which gave no inhibition zone by incubating overnight at $37^{\circ} \mathrm{C}$ were isolated as CPC or PCN negative mutants. The lack of antibiotic productivity was confirmed further by cultivation of the mutants in the fermentation medium at $28^{\circ} \mathrm{C}$ for 5 days.

Furthermore, these mutants were tested for the ability to grow on a Vogel minimal agar plate, ${ }^{\theta\rangle}$ and prototrophs were used in the subsequent experiments.

Determination of $\beta$-lactam antibiotics. The $\beta$-lactam antibiotics were determined by the paper disk method 
using the same test microorganisms as described above. Cephalosporin $\mathrm{C}$ was also assayed by the enzymatic method ${ }^{5,7)}$ based on the decrease of absorbance at $260 \mathrm{~nm}$ that depends on the degradation of CPC by the cephalosporinase. This $\beta$-lactamase was prepared by the same method as reported previously. ${ }^{5}$ )

Detection of sulfur-containing compounds. A loopful of cells grown on a slant agar was inoculated into a 200 -ml flask containing $10 \mathrm{ml}$ of the fermentation medium and the flask was incubated at $28^{\circ} \mathrm{C}$ for 2 days on a rotary shaker. And then, ${ }^{85} \mathrm{~S}-\mathrm{L}-\mathrm{methionine}(10 \mu \mathrm{Ci})$ was added aseptically into the culture broth and the culture was continued for another 3 days. The culture broth was centrifuged and a $50 \mu 1$ aliquot of the supernatant was applied to paper chromatography (Whatman No. 1 filter paper, butanol: acetic acid: water [4:1:4], $15 \mathrm{hr}$ at room temperature, descending). The paper was dried in air and sprayed with ninhydrin reagent $(5 \%$ ninhydrin in $70 \%$ ethanol). The paper was cut off into pieces at $0.5 \mathrm{~cm}$ of distance, and radioactivity of ${ }^{38} \mathrm{~S}$ in each piece was measured by an Aloka liquid scintillation counter with scintillation solvent containing naphthalene $(10 \%), 2,5$-diphenyloxazole $(1.2 \%)$, 1,4-bis[2-(5-phenyloxazolyl)]-benzene $(0.03 \%)$, dioxane $(72 \%, v / v)$, toluene $(13.5 \%, v / v)$ and methanol $(4.5 \%$, $\mathrm{v} / \mathrm{v})$.

Determination of the absolute configuration of amino acids. The configuration of amino acids was determined by the susceptibility test to L-amino acid oxidase. Deamination reaction was performed at $37^{\circ} \mathrm{C}$ for $16 \mathrm{hr}$ in a mixture ( $4 \mathrm{ml}$ ) containing $120 \mu$ moles of potassium phosphate buffer ( $\mathrm{pH} 7.6$ ) $0.2 \mu$ moles of FAD, $10 \mathrm{mg}$ of L-amino acid oxidase (type I), $20 \mathrm{mg}$ of catalase and amino acids to be tested (10 20 mg of samples). Residual amino acids were analyzed with a Hitachi KLA-3B amino acid analyzer. Under these conditions, L-cysteine, L-cystine, I- $\alpha$-aminoadipic acid and Lvaline were quantitatively deaminated.

Other analytical methods. Mass spectrum was recorded on a Hitachi RMS mass spectrometer operating at $70 \mathrm{eV}$. NMR spectra were recorded on a Varian HA-100 NMR spectrometer. Tetramethylsilane was used as an internal standard.

Materials. Penicillinase, $\mathrm{L}$-amino acid oxidase and catalase were purchased from Schwarz-Mann, Sigma and Boehringer Mannheim Co., Ltd., respectively. ${ }^{35} \mathrm{~S}$-L-Methionine $(40 \sim 500 \mathrm{mCi} / \mathrm{mm})$ was purchased from the Radiochemical Center, Amersham.

\section{RESULTS}

\section{Derivation of $\beta$-lactam negative mutants}

$\beta$-Lactam negative mutants of $C$. acremonium are expected to fall into three groups from a viewpoint of the production of antibiotics; PCN negative and CPC positive mutants (the first group), $\mathrm{PCN}$ positive and $\mathrm{CPC}$ negative mutants (the second group), $\mathrm{PCN}$ negative and CPC negative mutants (the third group). One hundred and nine mutants were originally isolated as PCN negative mutants, and 103 mutants, as CPC negative mutants. All the PCN negative mutants were classified into the third group. It was found that CPC negative mutants were devided into the second group (38 strains) and the third group (65 strains). Mutants of the first group were never isolated.

\section{Detection of products}

The mutants were cultivated in the fermentation medium and the culture broths were centrifuged. The compounds containing sulfur and positive to ninhydrin reaction were searched on the paper chromatograms of the supernatants.

The parent strain, No. 52 was found to produce PCN ( $R f$ value, 0.29 ), CPC ( $R f$ value, $0.18)$ and deacetylcephalosporin $\mathrm{C}(R f$ value, 0.11). Three PCN negative mutants, $\mathrm{N}-2$, $\mathrm{N}-31$ and $\mathrm{N}-79$, which belonged to the third group, were demonstrated to accumulate two unknown compounds. As shown in Fig. 1, radioactive fractions positive to ninhydrin reaction were named $\mathrm{S}-1$ ( $R f$ value, 0.30$)$ and $\mathrm{S}-2$ ( $R f$ value, 0.69 ), respectively. The presence of sulfur in S-2 was appreciated by the paper electrophoresis (Whatman No. 1 filter paper,

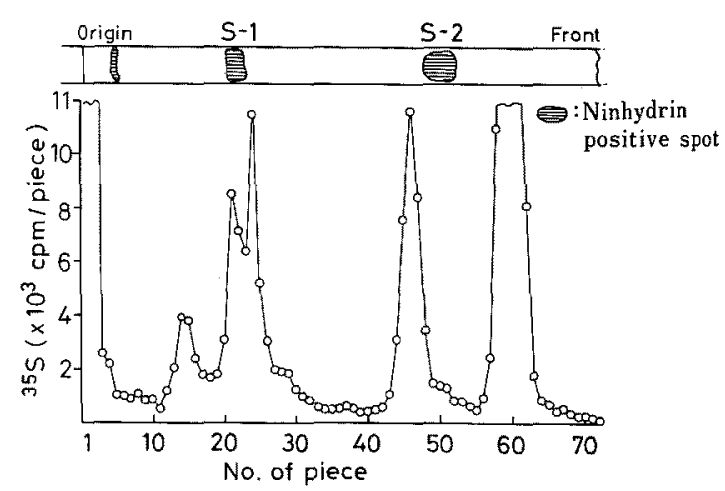

FIG. 1. Paper Chromatogram of Culture Broth of Mutant N-2. 
$95 \mathrm{~V} / \mathrm{cm}, 30 \mathrm{~min}, 0.1 \mathrm{M}$ of formate buffer, pH 2.8). S-2 migrated $8 \mathrm{~cm}$ toward the cathode, and an unknown compound containing ${ }^{35} \mathrm{~S}$ moved $5 \mathrm{~cm}$ toward the anode. The latter compound was negative to ninhydrin reagent.

\section{Isolation of $S-1$ and $S-2$}

The mutant, $\mathrm{N}-2$ was cultivated at $28^{\circ} \mathrm{C}$ for 5 days in 50 liters of the fermentation medium in a 100 liter fermentor with agitation. The culture broth was ajusted to $\mathrm{pH} 3.5$ with $\mathrm{HCl}$, and filtered. The filtrate (43 liters) was loaded on 20 liters of an activated carbon column. The column was washed with 100 liters of water and 100 liters of $10 \%$ acetonewater. The products were eluted with 100 liters of $60 \%$ acetone-water. This eluate was concentrated to $800 \mathrm{ml}$ and kept to stand at $4^{\circ} \mathrm{C}$ overnight. The precipitate was collected on a glass filter (No. 3), and washed with $100 \mathrm{ml}$ of cold $60 \%$ acetone-water and $100 \mathrm{ml}$ of acetone. After dryness over $\mathrm{P}_{2} \mathrm{O}_{5}$ in vacuo, $7.2 \mathrm{~g}$ of crude powder was obtained.

S-1 and $\mathrm{S}-2$ in the crude powder were separated by gel filtration through a Sephadex G-15 column $(3.2 \times 135 \mathrm{~cm}$, developed with $0.1 \mathrm{M}$ of acetic acid). Fractions containing S-1 were combined, concentrated and allowed to stand at $4^{\circ} \mathrm{C}$. Colorless needles were filtered and washed with $10 \mathrm{ml}$ of cold water and $10 \mathrm{ml}$ of acetone. After dryness over $\mathrm{P}_{2} \mathrm{O}_{5}$ in vacuo, $1.3 \mathrm{~g}$ of S-1 were obtained from $2 \mathrm{~g}$ of the crude powder.

S-2 fractions were concentrated to $5 \mathrm{ml}$, and the gel filtration was repeated under the same condition. The $\mathrm{S}-2$ fractions were loaded on a Dowex $50 \times 12$ column $\left(2.5 \times 7.0 \mathrm{~cm}, \mathrm{H}^{+}\right.$form, $100 \sim 200$ mesh) and eluted with $1 \mathrm{~N}$ of $\mathrm{NH}_{4} \mathrm{OH}$. The eluate was concentrated as soon as possible, and applied to Dowex $1 \times 2$ column chromatography $(2.0 \times 15 \mathrm{~cm}$, acetate-form, $100 \sim 200$ mesh). S-2 was developed with a linear gradient of $0.05 \mathrm{M}$ to $1.0 \mathrm{M}$ acetate buffer (pH 5.0). The S-2 fractions were desalted by activated carbon column chromatography $(2.0 \times 15 \mathrm{~cm})$, concentrated and lyophilized. After dryness, $40 \mathrm{mg}$ of S-2 was obtained as white powder from $2 \mathrm{~g}$ of the crude powder.

\section{Chemical characterization $S, S-1$ and $S-2$}

a) Amino acids in $S-1$. Equimolar amounts of $\alpha$-aminoadipic acid, cysteine and valine were determined to be present in the hydrolyzate of S-1 (Table I). The susceptibility test to L-amino acid oxidase showed that $\alpha$-aminoadipic acid, cysteine and valine have L-, L- and D-configuration, respectively.

Tabee I. Amino Acios of S-1

The compound $\mathrm{S}-1(10.3 \mathrm{mg})$ was hydrolyzed with $2 \mathrm{ml}$ of $6 \mathrm{~N} \mathrm{HCl}$ in a sealed tube at $110^{\circ} \mathrm{C}$ for $24 \mathrm{hr}$, and the hydrolyzate equivalent to $0.536 \mathrm{mg}$ of sample as $\mathrm{S}-1$ was analyzed after removal of $\mathrm{HCl}$ in vacuo. Another aliquot of the hydrolyzate was submitted to L-amino acid oxidase treatment and the deaminated sample $(0.248 \mathrm{mg}$ as $\mathrm{S}-1)$ was analyzed.

\begin{tabular}{ccrcc}
\hline & \multicolumn{4}{c}{ Amino acid $\mu$ mole } \\
\cline { 2 - 5 } & $\alpha-\mathrm{Aa}$ & Cys & Cys-SO $_{3}$ & \multicolumn{1}{c}{ Val } \\
\hline Hydrolyzed & 1.51 & 1.41 & 0.01 & 1.38 \\
& $(102.0)^{a}$ & $(95.3)$ & $(0.6)$ & $(93.2)$ \\
Deaminated & 0.02 & 0.01 & 0.00 & 0.72 \\
& $(3.3)$ & $(1.7)$ & $(0.0)$ & $(121.8)$ \\
\hline
\end{tabular}

$\alpha$-Aa: $\alpha$-aminoadipic acid. Cys: cysteine. $\overline{\mathrm{Cys}-\mathrm{SO}_{3}}$ cysteic acid. Val: valine. ${ }^{a}$ : Recovery in percent. Recovery values in parentheses were calculated on the basis of the theoretical value when $S-1$ was assumed to be the dimer of the tripeptide, $\alpha$-aminoadipylcysteinylvaline.

The amino acid residue with a free amino group in $\mathrm{S}-1$ was determined to be $\alpha$-aminoadipic acid by the fluorodinitrobenzene method. ${ }^{8)}$

The titration curve of $\mathrm{S}-1\left(\mathrm{pKa}^{\prime} ; 9.7,3.9\right.$ and 3.2) suggested that the carboxylic acid at the $\alpha$-position of $\alpha$-aminoadipic acid was free, because the $\mathrm{pKa}$ ' values of the carboxylic acid at $\alpha$ - and $\delta$-position of this amino acid were 2.2 and 4.4 , respectively. ${ }^{9 \text { ? }}$

b) Reduction of $S-1$ and $S-2$. Both compounds were proved to have no free thiol group in spite of the presence of cysteine in the molecules, because they were negative to starch-iodine test. However, they became positive to the test after treatment with a reducing agent, dithiothreitol. In addition, both compounds yielded the same product 
Table II. Chromatography of S-1, S-2, AND Their Reduced Compounds

Values in system 1 and 2 are $R f$ and those in system 3 show relative distance when glutathione is 1.00 . Thin-layer chromatography was carried out on silica gel sheets (Eastman) in the following solvent systems; system 1,75\% propanol and system 2, $n$-butanol: acetic acid: water $(3: 1: 1, \mathrm{v} / \mathrm{v})$. Descending paper chromatography was performed on Whatman No. 1 filter paper in system 3 which consisted of $n$-butanol: acetic acid: water $(4: 1: 1, v / v)$. Reduction was carried out by standing for $60 \mathrm{~min}$ at $28^{\circ} \mathrm{C}$ in the solution containing $10 \mathrm{~mm}$ dithiothreitol and $0.1 \mathrm{M}$ $\mathrm{NaHCO}_{3}$.

\begin{tabular}{lccc}
\hline \multirow{2}{*}{ Compound } & \multicolumn{3}{c}{ System } \\
\cline { 2 - 4 } & 1 & 2 & 3 \\
\hline S-1 & 0.40 & 0.30 & 1.40 \\
Reduced S-1 (S) & 0.58 & 0.54 & 2.86 \\
S-2 & 0.66 & 0.60 & 3.50 \\
Reduced S-2 (S) & 0.57 & 0.53 & 2.85 \\
Glutathione & 0.45 & 0.32 & 1.00 \\
\hline
\end{tabular}

(named as S) by this treatment as shown in Table II. This evidence suggested that S-1 and $\mathrm{S}-2$ contained the common thiol-containing compound, $\mathrm{S}$, which was positive to ninhydrin reagent.

c) Identification of $S$. The evidences described above remainded us of the tripeptide reported by Loder et al. $^{10}$ They showed that the amino acid sequence of the peptide was able to be determined by the Mass spectrum of the N,S-ethoxycarbonyl derivative of its methylester.

Reduction, N,S-ethoxycarbonylation and methylation of $\mathrm{S}-1$ were performed according to their methods. The Mass spectrum of this derivative of $\mathrm{S}$ showed a good agreement with that of the tripeptide, as shown in Fig. 2. The parental peak at $m / e 535$ and fragment peaks at $m / e 405$ and 230 clearly showed that $S$ was the tripeptide, $\alpha$-aminoadipylcysteinylvaline. Furthermore, the fragment ion, $m / e 387$ was also observed, which indicated the $\delta$-linkage of $\alpha$-aminoadipic acid.

The chemical structure of $\mathrm{S}$, the common constituent of $S-1$ and $S-2$, was also examined by recording NMR spectrum in trifluoroacetic acid. Proton signals were assigned by $\mathrm{D}_{2} \mathrm{O}$ displacement and by comparison with the spectra of peptides including glutathione. ${ }^{11)}$

The NMR spectra of $S$ are shown in Fig. 3a. A triplet signal at $\delta 1.72 \mathrm{ppm}(1 \mathrm{H}, \mathrm{t}, J=8 \mathrm{~Hz})$, which disappeared by $\mathrm{D}_{2} \mathrm{O}$ displacement, attributed to a proton of the thiol group in cysteine, although the sulfhydryl proton was not recorded in the case of glutathione. ${ }^{11)}$ Two methyl protons of valine were observed at $\delta 1.08 \mathrm{ppm}$ and $1.12 \mathrm{ppm}(3 \mathrm{H} \times 2, \mathrm{~d}, J=7 \mathrm{~Hz})$. Multiplet signals centered at $\delta 2.17 \mathrm{ppm}(5 \mathrm{H})$ were assigned to four protons at the $\beta$ and $\gamma$ position of $\alpha$-aminoadipic acid, and to a proton at the $\beta$ position of valine. The protons at the $\delta$ position of $\alpha$-aminoadipic acid were observed at $\delta 2.62 \mathrm{ppm}(2 \mathrm{H}, \mathrm{t}, J=7 \mathrm{~Hz})$. The triplet signal at $\delta 2.99 \mathrm{ppm}(2 \mathrm{H}, \mathrm{t}, J=$ $7 \mathrm{~Hz}$ ) attributed to the protons at the $\beta$ position of cysteine. $\mathrm{D}_{2} \mathrm{O}$ displacement changed this signal to the doublet $(J=7 \mathrm{~Hz})$. Signals at $\delta 4.84 \mathrm{ppm}(1 \mathrm{H}, \mathrm{q}, J=7,13 \mathrm{~Hz}), \delta 4.64 \mathrm{ppm}$ $(1 \mathrm{H}, \mathrm{q}, J=5,9 \mathrm{~Hz})$ and $\delta 4.36 \mathrm{ppm}(1 \mathrm{H}, \mathrm{m})$ were also assigned to protons at the $\alpha$ position of $\alpha$-aminoadipic acid, valine and cysteine, respectively. The four protons at $7.0 \sim 8.0$

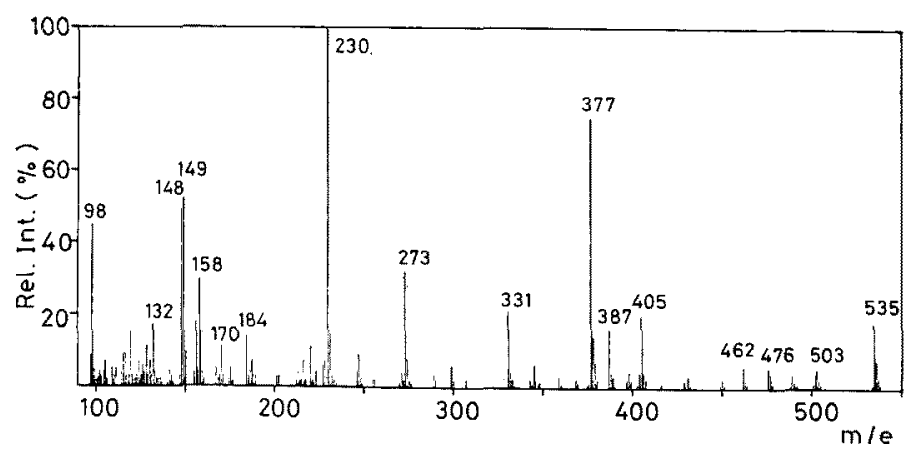

FIG. 2. Mass Spectrum of N,S-Ethoxycarbonyl Derivative of "S" Methyl Ester. 


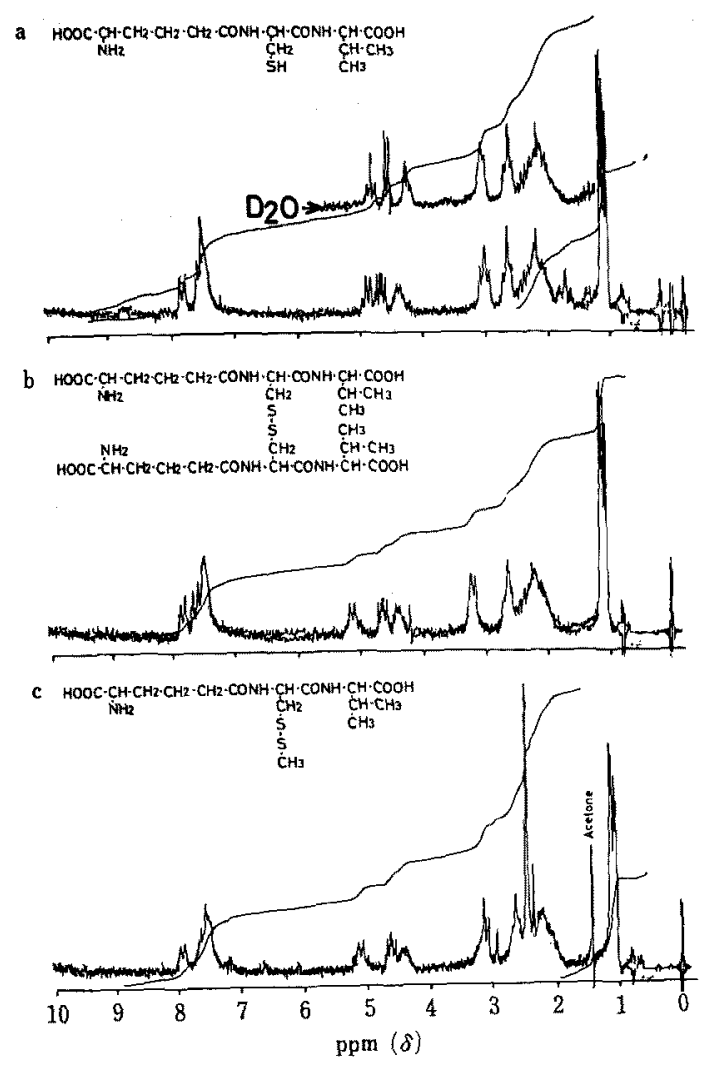

FIg. 3. NMR Spectra of Products in $\mathrm{CF}_{8} \mathrm{COOH}$ at $100 \mathrm{MHz}$.

a: $\mathrm{S}$ (reduced derivative of $\mathrm{S}-1$ ). $\quad$ b: $\mathrm{S}-1 . \quad \mathrm{c}: \mathrm{S}-2$.

ppm were assigned to protons of amino and amide groups.

d) Chemical structure of $S-1$ and $S-2$. The NMR spectrum of $\mathrm{S}-1$ (Fig. 3b) was very similar to that of $\mathrm{S}$ (Fig. 3a) with the exceptions of the signal of the thiol group and those due to the $\beta$ position of cysteine. The former disappeared and the latter was observed at $3.21 \mathrm{ppm}(2 \mathrm{H}, \mathrm{d}, J=7 \mathrm{~Hz})$. These results together with the aforementioned observations indicated that the structure of $S-1$ have the disulfide form of $S$.

The spectrum of S-2 (Fig. 3c) was almost the same as that of S-1 (Fig. 3b), except for a sharp singlet signal at $\delta 2.44$ ppm $(3 \mathrm{H})$ due to protons of methyl group. Reduction of S-2 with dithiothreitol gave the reducing compound, $S$ (Table II). These results showed that $S-2$ was the methylthio derivative of $S$.

Then, the structure of $\mathrm{S}-2$ was confirmed by

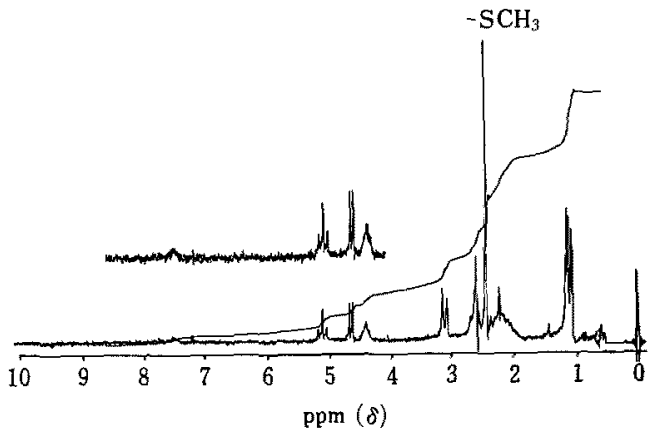

FlG. 4. NMR Spectrum of S-Methylthio Derivative of "S" in $\mathrm{CF}_{3} \mathrm{COOD}$ at $100 \mathrm{MHz}$.

transferring methylthio group of S-methylthiothiourea to $S$, according to the method of Sirakawa et $a l^{121}$ The reaction product was purified and isolated by activated carbon column chromatography and gel filtration with Sephadex G-15 (yield, 70\%). The NMR spectrum of this methylthio derivative synthesized was identical with that of S-2, as shown in Fig. 4. The identity was also shown by thin-layer chromatography.

Elementary analyses of $S-1$ and $S-2$ supported the aforementioned results. $\mathrm{S}-1$; calculated for $\mathrm{C}_{28} \mathrm{H}_{48} \mathrm{~N}_{8} \mathrm{O}_{18} \mathrm{~S}_{2} \cdot 2 \mathrm{H}_{2} \mathrm{O}: \mathrm{C}, 44.19$; $\mathrm{H}, 6.88 ; \mathrm{N}, 11.04 ; \mathrm{S}, 8.48 \%$, found: $\mathrm{C}, 44.68$; $\mathrm{H}, 6.46 ; \mathrm{N}, 10.96 ; \mathrm{S}, 8.23 \%$. S-2; calculated for $\mathrm{C}_{15} \mathrm{H}_{27} \mathrm{~N}_{3} \mathrm{O}_{6} \mathrm{~S}_{2} \cdot 2 \mathrm{H}_{2} \mathrm{O}: \mathrm{C}, 40.39 ; \mathrm{H}, 7.01$; N, 9.43 ; S, $14.39 \%$, found: C, 39.54; H, 6.01; $\mathrm{N}, 8.78 ; \mathrm{S}, 12.51 \%$.

\section{DISCUSSION}

The $\beta$-lactam antibiotic biosynthesis in $C$. acremonium was studied by examining the antibiotic negative mutants which were expected to produce the intermediates or their derivatives. One of the PCN negative mutants, $\mathrm{N}-2$ was found to accumulate extracellularly two sulfur- containing peptides, $\mathrm{S}-1$ and $\mathrm{S}-2$. These peptides were the derivatives of $S, \delta$ (L- $\alpha$-aminoadipyl)-L-cysteinyl-D-valine. This tripeptide is identical with one of the peptides (P3) reported by Loder et al. ${ }^{10}$ which were purified and isolated as cuprous mercaptides from the mycelia of Cephalosporium sp.

S-1 was the disulfide form of $S$, which was 
probably oxidized nonenzymatically owing to the oxidative fermentation. $\mathrm{S}-2$ was the $\mathrm{S}$ methylthio derivative of $\mathrm{S}$. It was supposed that methanthiol released from methionine was transferred to $\mathrm{S}$. The total amount (about $1.65 \mu \mathrm{moles} / \mathrm{ml}$ as $\mathrm{S}$ ) of these tripeptides produced by the mutant was similar to that of $\beta$-lactam antibiotics produced by the parental strain in the same culture condition.

The accumulation of these peptides by the $\beta$-lactam negative mutant suggests that the peptides play an important role for the biosynthesis of the antibiotics. However, the tripeptide, $\mathrm{S}$ is likely a real intermediate.

Our mutants (N-2, $\mathrm{N}-31$ and $\mathrm{N}-79$ ) are supposed to be blocked on a certain step after the tripeptide formation, and thus did not produce CPC and PCN. This result suggests that both the antibiotics are biosynthesized through one or more common steps after the tripeptide formation. The $\beta$-lactam negative mutants were also derived by Lemke and Nash. ${ }^{13}$ They reported that a group of such mutants did not incorporate ${ }^{14} \mathrm{C}$-labeled valine and $\alpha$-aminoadipic acid into cuprous mercaptides. Their mutants seem to be blocked on a step before the tripeptide formation.

Recently, Fawcett et $a l^{14,15)}$ demonstrated a more direct evidence that the ${ }^{3} \mathrm{H}$-labeled tripeptide was incorporated into PCN. However, the precise mechanism of cyclization of the tripeptide remains to be revealed.

Acknowledgement. The authors are indebted to Dr. R. Takeda, Dr. M. Isono and Dr. H. Fukuda for suggestions and encouragement. We thank Dr. M. Numata for the helpful advice of identification and preparation of methylthio derivative of the tripeptide.

\section{REFERENCES}

1) E. P. Abraham and G. G. F. Newton, "Antibiotics," Vol. 2, ed. by D. Gottlieb and P.D. Shaw, Springer-Verlag, New York, 1967, p. 1.

2) A. L. Demain, "Biosynthesis of Antibiotics," Vol. 1, ed. by J. F. Snell, Academic Press, New York and London, 1966, p. 29.

3) P.A. Lemke and D.R. Brannon, "Cephalosporins and Penicillins," ed. by E. H. Flynn, Academic Press, New York and London, 1972, p. 370.

4) E. P. Abraham and G. G. F. Newton, Biochem. J., 79, 377 (1961).

5) Y. Fujisawa, H. Shirafuji, M. Kida, K. Nara, M. Yoneda and T. Kanzaki, Agric. Biol. Chem., 39, 1295 (1975).

6) H. J. Vogel, Microbiol. Genet. Bull., 13, 42 (1956).

7) Y. Fujisawa, H. Shirafuji, M. Kida, K. Nara, M. Yoneda and T. Kanzaki, Nature New Biol., 246, 154 (1973).

8) R. R. Porter, "Methods in Enzymology," Vol. 4, ed. by S.P. Colowick and N.O. Kaplan, Academic Press Inc., New York, 1957, p. 221.

9) G. G. F. Newton and E. P. Abraham, Biochem.J., 58, 101 (1954).

10) P. B. Loder and E. P. Abraham, ibid., 123, 471 (1971).

11) F. A. Bovey and G. V. D. Tiers, J. Am. Chem. Soc., 81, 2870 (1959).

12) K. Shirakawa, O. Aki, T. Tsujikawa and T. Tsuda, Chem. Pham. Bull, 18, 235 (1970).

13) P. A. Lemke and C. H. Nash, Can. J. Microbiol., 18, 255 (1971).

14) P. A. Fawcett, J. J. Usher and E. P. Abraham, "The 2nd Internationsl Symposium on Genetics of Industrial Microorganisms,", ed. by K.D. Macdonald, Academic Press, London, New York and San Francisco, 1976, p. 129.

15) P. A. Fawcett, J. J. Usher, J. A. Huddleston, R. C. Bleaney, J. J. Nisbet and E. P. Abraham, Biochem. J., 157, 651 (1976). 